\title{
Nonionic polyol esters as thinner and lubricity enhancer for synthetic-based drilling fluids
}

\begin{abstract}
This study evaluates the performance of polyol esters as thinners and lubricity enhancers in invert emulsion synthetic-based drilling mud (SBM). Three types of polyol esters, namely pentaerythritol ester (PEE), trimethylolpropane ester (TMPE), and neopentyl glycol ester (NPGE), were prepared at various concentrations of 1, 2, and 3\% (v/v) in SBM. The results showed that polyol esters reduced the rheological properties of the drilling mud, such as yield point and gel strength, after the hot rolling test at $135^{\circ} \mathrm{C}$. The rheology data was fitted to the Herschel-Bulkley model to describe the shear thinning behaviour of drilling mud. The model parameters showed that the polyol ester resulted in lower yield stress of SBM, which indicated lower forces are needed to initiate a fluid to move. Their relative effectiveness as a lubricity enhancer was evaluated by measuring the coefficient of friction (COF), wear scar diameter, and scar topography. It was found that polyol esters reduced the COF of SBM by $22 \%$ at a concentration of $1 \%(\mathrm{v} / \mathrm{v})$. PEE provided the best friction reduction and anti-wear performance due to a higher number of the ester group and molecular weight, in comparison with NPGE and TMPE. The lubricity improvement for SBM is recently required by off-shore regulations.
\end{abstract}

Keyword: Polyol ester; Rheology modifier; Drilling mud; Wear prevention 